\title{
Response of human HT-29 colorectal tumor cells to extended exposure to bromodeoxyuridine
}

\author{
Jonathan Maybaum*1, Mikehl S. Hafner ${ }^{2}$, Eric C. Burton², Philip L. Stetson ${ }^{2}$, William D. Ensminger ${ }^{2,3}$, \\ and Clare E. Rogers ${ }^{3}$ \\ ${ }^{2}$ Department of Pharmacology, University of Michigan Medical School \\ ${ }^{3}$ Department of Internal Medicine, University of Michigan Medical School
}

Summary. Effects of the extended exposure of a human colorectal tumor-cell line (HT-29) to bromodeoxyuridine (BrdUrd) were studied in anticipation of the clinical use of that agent to treat colorectal cancer, particularly as a regionally delivered radiosensitizer. We found that $72-\mathrm{h} \mathrm{ex}$ posure to a concentration of BrdUrd that is estimated to be locally maintained in the liver $(100 \mu M)$ was significantly cytotoxic with a 3-log reduction in survival. As measured by GC/MS-SIM method, incorporation of BrdUrd into DNA followed an unexpected time course in that continuous exposure to $10 \mu \mathrm{MBrdUrd}$ resulted in maximal incorporation at 3 days, after which the extent of incorporated analog fell significantly (despite daily changes of the medium). This finding was apparently due to a greater rate of loss of BrdUrd from the medium at later time points. Flow cytometric analysis using an anti-BrdUrd antibody (IU-4) revealed that antibody binding also peaked and fell off with time. However, at exposure times of $>24 \mathrm{~h}$, the timing and extent of this decline were significantly different than had been indicated by the GC/MS method. These results indicate that the quantitative relationship between antibody staining and BrdUrd incorporation changes as drug-exposure time increases and that quantitative studies of anti-BrdUrd antibody binding must be interpreted with caution, especially when extended drug-treatment protocols have been used.

\section{Introduction}

The 5-halopyrimidines bromodeoxyuridine (BrdUrd) and iododeoxyuridine (IdUrd) exert a multitude of biological effects, many of which have been attributed to their incorporation into DNA in place of dThd (reviewed by Goz [12]). Of these effects, the one that has been explored most extensively with regard to therapeutic application is the enhanced sensitivity to radiation that accompanies such incorporation $[6,10,26]$. Other potentially beneficial effects of halopyrimidine incorporation, such as alteration of differentiation state and outright cytotoxicity, have been less well characterized.

\footnotetext{
* Recipient of a Faculty Development Award from the Pharmaceutical Manufacturers Association Foundation

Offprint requests to: J. Maybaum, 4302A Upjohn Center for Clinical Pharmacology, University of Michigan Medical School, Ann Arbor, MI 48109-0504, USA
}

For treatment with an incorporated radiosensitizer to be effective in vivo, the duration of treatment should be sufficiently long to enable the greatest possible fraction of tumor cells to traverse S-phase in the presence of the drug. Even with such an extended treatment, analog incorporation is likely to be heterogeneous within the subject population. In recognition of this factor, antibodies that bind to incorporated BrdUrd have been used to assess the distribution of BrdUrd incorporation in tumor sections taken from patients treated with this agent $[13,17,21]$. With such an approach it may be possible not only to extract qualitative information concerning the presence or absence of analog incorporation in cells in specified regions of tumor sections, but also to provide a quantitative measure of such incorporation. Initial results have indicated that antiBrdUrd binding is proportional to incorporation under some conditions [7]. However, these experiments were carried out using relatively short drug-exposure times. Since BrdUrd incorporation is known to alter chromatin structure and stability, and since some of the biological effects of BrdUrd treatment do not become evident until several generations of exposure, the relationship between analog incorporation and antibody-mediated staining may not be constant throughout an extended exposure to the drug.

We are currently investigating the use of BrdUrd as a regionally (hepatic-arterially) delivered sensitizer of colorectal and hepatic tumors in animal models and humans. Since these studies will necessarily entail extended periods of drug exposure, we felt that the design and evaluation of treatment schedules would benefit from knowledge of the response of tumor cells to prolonged exposure to this agent, particularly with respect to the relationship between anti-BrdUrd antibody staining and actual BrdUrd incorporation. We therefore studied the response of one human colorectal tumor cell line (HT-29) to continuous treatment with BrdUrd for up to 1 week.

\section{Materials and methods}

Cell culture and drug treatments. HT-29 cells were purchased from the American Type Culture Collection (Rockville, Md) and grown as monolayers in McCoy's 5A medium (Gibco, Grand Island, NY) supplemented with 10\% fetal bovine serum (Gibco) at $37^{\circ} \mathrm{C}$ in a $5 \% \mathrm{CO}_{2}$ atmosphere. For each experiment, cells were subcultured by trypsinization, plated at a density of $20,000 / \mathrm{cm}^{2}$, and allowed to recover for $24 \mathrm{~h}$ before the addition of drug. All 
manipulations were carried out under yellow incandescent light. medium was renewed daily in experiments lasting $>24 \mathrm{~h}$. Cloning assays were done by trypsinizing drugtreated cells and replating appropriate dilutions into 60-mm tissue-culture dishes. Cells were fixed and stained after 14 days of incubation and colonies ( $\geq 50$ cells) were counted manually.

Flow cytometry. Trypsinized cells were washed and resuspended in Hanks' buffered saline solution (HBSS, Gibco), then fixed by the dropwise addition of 2.5 vol. cold $70 \%$ $\mathrm{EtOH}$ and stored at $4^{\circ} \mathrm{C}$ until the day of analysis, at which point they were denatured and stained using a minor modification of a previously published procedure $[2,8]$. Cells were centrifuged at $1,400 \mathrm{~g}$ for $2 \mathrm{~min}$ and resuspended in $1 \mathrm{ml} \mathrm{HBSS}$ containing $0.25 \%$ paraformaldehyde for 30 min at room temperature. Cells were then gently pellted again, resuspended in $1 \mathrm{ml}$ HBSS containing $0.5 \mathrm{mg}$ RNase (Sigma Chemical Co.), and incubated at $37^{\circ} \mathrm{C}$ for $20 \mathrm{~min}$, after which they were again spun down and resuspended in $1 \mathrm{ml} 0.1 \mathrm{~N} \mathrm{HCl}$ containing $0.5 \%$ Triton X-100 for $10 \mathrm{~min}$ at room temperature. At this point, $5 \mathrm{ml}$ distilled water was added and the cells were spun down again, resuspended in $1 \mathrm{ml}$ water, and heated to $100^{\circ} \mathrm{C}$ for $10 \mathrm{~min}$. Thereafter, the cells were immdiately placed on ice for $5 \mathrm{~min}$, washed once with $1 \mathrm{ml}$ HBSS containing $0.5 \%$ Tween-20, and suspended in $100 \mu \mathrm{l}$ solution containing the anti-BrdUrd antibody IU-4 [27], a gift from Dr. F. Dolbeare) diluted 1:500 from ascites fluid with diluting buffer (HBSS, $0.5 \%$ Tween-20, 0.1\% bovine serum albumin). This was allowed to incubate at room temperature for $30 \mathrm{~min}$, after which cells were washed once with $2 \mathrm{X}$ SSC $[0.3 M$ $\mathrm{NaCl}, 0.03$ sodium citrate (pH 7.4)], resuspended in $100 \mu 1$ $1: 100$ dilution of fluorescein-conjugated goat anti-mouse IgG (Sigma) in diluting buffer, and incubated for an additional $30 \mathrm{~min}$. Finally, the cells were washed once with $2 \mathrm{X}$ SSC and suspended in $1 \mathrm{ml}$ HBSS containing $16.7 \mu \mathrm{g} / \mathrm{ml}$ propidium iodide. Samples were analyzed on an EPICS C flow cytometer (Coulter Electronics) using a 514-nm bandpass filter for green fluorescence and a $600-\mathrm{nm}$ long-pass filter for red fluorescence, with excitation at $488 \mathrm{~nm}$.

Analysis of BrdUrd incorporation. this procedure has recently been reported in detail $[20,24]$. Briefly, DNA was isolated by the lysis of cells in a sodium dodecyl sulfate (SDS)-containing buffer, followed by proteinase and RNase digestion and ethanol precipitation. Enzymatic hydrolysis with DNase I, phosphodiesterase, alkaline phosphatase, and thymidine phosphorylase liberated incorporated 5-bromouracil and thymine. After the addition of 5-chlorouracil as an internal standard, the bases were then extracted into ethyl acetate and derived with bis-trimethylsilyl trifluoroacetamide. Quantitation of the derived products was carried out using a Hewlett-Packard 5987A gas chromatograph/mass spectrometer (GC/MS) in the selected ion-monitoring (SIM) mode.

Analysis of BrdUrd content in culture medium as a function of time. Tissue-culture flasks $\left(150 \mathrm{~cm}^{2}\right)$ plated with 0 , $3 \times 10^{6}$ (low density) or $12 \times 10^{6}$ (high density) HT29 cells were incubated at $37^{\circ} \mathrm{C}$ with $30 \mathrm{ml}$ medium containing $10 \mu M$ BrdUrd for $48 \mathrm{~h}$. Aliquots $(3 \mathrm{ml})$ were periodically withdrawn and analyzed for BrdUrd content by a previously published HPLC method [23].

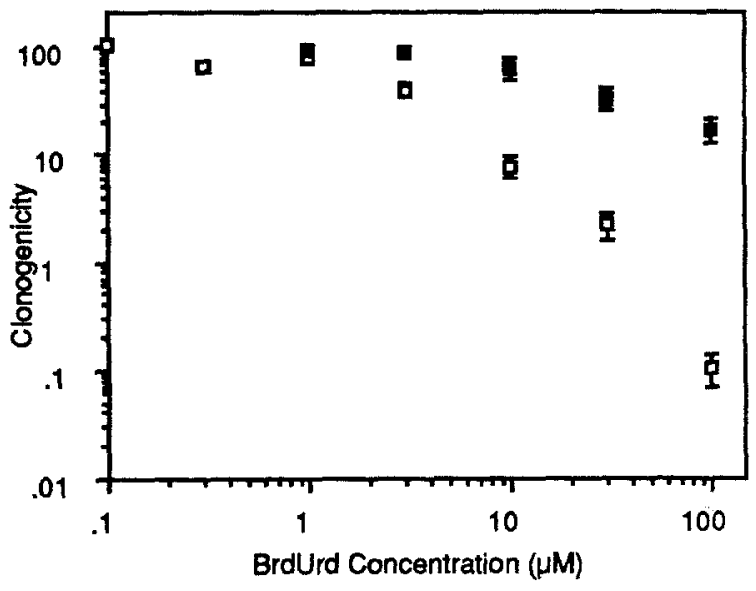

Fig. 1. Loss of clonogenicity due to BrdUrd treatment. HT29 cells were exposed to the indicated concentrations of BrdUrd for either $24(\boldsymbol{\square})$ or 72 ( $\square$ ) h, after which clonogenicity was assayed as described in the text. Data represent the mean \pm SE of 3-4 experiments in which triplicate determinations were made at each concentration. Clonogenicity is expressed as the percentage of control plating efficiency, which was typically $70 \%-75 \%$

\section{Results and discussion}

\section{BrdUrd-induced loss of clonogenicity in HT29 cells}

BrdUrd is often used to density-label DNA in living cells and, although its growth inhibitory properties have been demonstrated in many circumstances, its effects on clonogenicity have infrequently been reported. As shown in Fig. 1, exposure of HT29 cells to concentrations as high as $100 \mu M$ for $24 \mathrm{~h}$ (one doubling time for this cell line) reduces clonogenicity by $<1$ log. Longer incubations elicit a considerably greater degree of cytotoxicity, however, as illustrated by the 2- to 3-log cell kill induced by $30-100 \mu \mathrm{M}$ BrdUrd exposure for $72 \mathrm{~h}$. although these concentrations could not be tolerated in the systemic circulation in humans due to bone marrow toxicity, regional delivery of this agent could produce locally cytotoxic concentrations while producing tolerable systemic plasma levels. For example, Kinsella et al. [16] have reported that systemic BrdUrd levels on the order of $1 \mu M$ can be tolerated in patients for 14 days. Assuming a regional advantage of $25-$ to 50-fold for hepatic arterial infusion, such a treatment would result in exposure of hepatic tumors to $25-50 \mu \mathrm{M}$ BrdUrd for an extended period of time [9]. If the sensitivity of a given colorectal cancer in vivo is similar to that exhibited by HT29 cells in this study, an approx. 2-log cell kill might be achieved (in addition to radiosensitization of surviving cells).

\section{Concentration dependence of BrdUrd incorporation}

The parameter most obviously associated with the biological effects of BrdUrd is the extent of this radiosensitizer's replacement of dThd in DNA. Sensitization to X-irradiation has been consistently correlated with 5 -halopyrimidine incorporation $[6,10,26]$. In addition, a number of studies in cell-free systems have demonstrated the alteration of DNA-protein interactions as a consequence of the presence of incorporated BrdUrd [3, 4, 11]. However, there are also instances in which the gross extent of BrdUrd incorporation has not correlated with its biological effect 


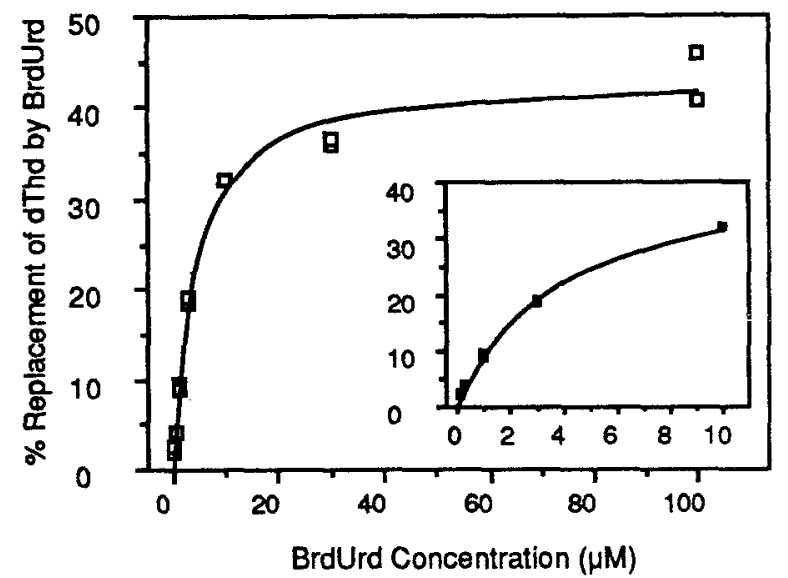

Fig. 2. Concentration dependence of BrdUrd incorporation. Cells were treated with BrdUrd for $24 \mathrm{~h}$ at the indicated drug concentrations, then harvested and analyzed for replacement of dThd by BrdUrd in DNA using the GC/MS-SIM method referred to in the text. A representative experiment is shown in which duplicate samples were obtained at each concentration (except $10 \mu M$, one of which samples was lost in this experiment). The data were fitted to Eq. 1 using a weighted least-squares method and the line shows the curve resulting from this fit. Inset: The same experiment with an expanded abscissa in the $0-10 \mu M$ range

$[15,22]$. Therefore, until the role of such incorporation is more clearly understood with respect to cellular functions, we intend to use incorporation data primarily as an index of expected radiosensitization.

To compare the intrinsic ability of various cells to incorporate BrdUrd, or to assess the relative efficacy of various agents to modulate incorporation in a given cell line, it would be useful to be able to quantitatively determine a parameter that reflects the concentration dependence of incorporation under given experimental conditions. Since we found in a previous study that the extent of BrdUrd incorporation into DNA in tissues from animals infused with that agent could be related to the dose rate by a rectangular hyperbolic function analogous to the MichaelisMenton equation [25], a similar type of analysis was carried out on incorporation values obtained after treatment of HT29 cells with a wide range of BrdUrd concentrations for $24 \mathrm{~h}$. Figure 2 shows the levels of incorporation observed at each drug concentration as well as the line describing the best fit of these data to Eq. 1. The variables in this equation include: $\mathrm{I}$, the extent of incorporation (i.e., replacement of dThd by BrdUrd); $\mathrm{C}$, the drug concentration in the medium; $I_{\max }$, the extent of incorporation estimated at infinite drug concentration; and $\mathrm{C}_{50}$, the drug concentration yielding $50 \%$ of maximal incorporation.

$I=\frac{\left(I_{, a x}\right)(C)}{\left(C_{50}+C\right)}$

For this experiment we calculated values of $43.3 \%$ $( \pm 1.1 \%)$ for $\mathrm{I}_{\max }$ and $3.82 \mu M\left( \pm 0.41 \mu M\right.$ for $\mathrm{C}_{50}$. Similar values were obtained in a duplicate experiment. Since the duration of exposure in this experiment was one doubling time, the greatest extent of incorporation that should be possible is $50 \%$, corresponding to complete replacement of dThd by BrdUrd in the newly replicated DNA strand. The observed value for $I_{\max }$ of $43.3 \%$ implies an actual maximal substitution rate of about $87 \%$ under these conditions, with

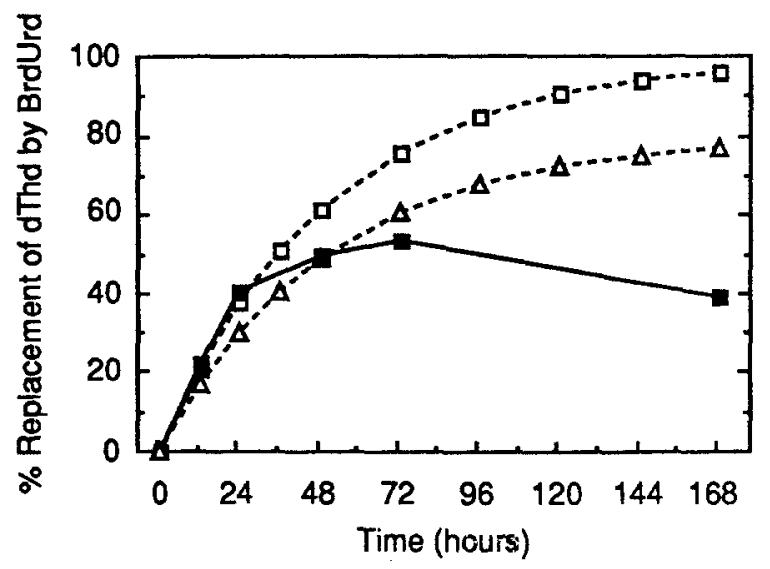

Fig. 3. Time dependence of BrdUrd incorporation. Cells were continuously exposed to $10 \mu M$ BrdUrd for various times (with daily medium changes), after which DNA incorporation of the analog was assayed by GC/MS-SIM. Data points (ש) represent the mean values for triplicate flasks within a single, typical experiment. Standard error bars are not shown, as they did not exceed the size of the symbols. The broken line with open boxes denotes the time course of incorporation that would be predicted if the population grew with a constant doubling time of $35.1 \mathrm{~h}$ (the average value observed with exposure to $10 \mu M$ BrdUrd; Table 1), assuming that replacement of dThd by BrdUrd occurred with $100 \%$ efficiency during each round of replication. The broken line with open triangles represents a similar projection, assuming only $80 \%$ replacement of dThd

the difference presumably due to continued incorporated of dTTP derived from the de novo pathway.

\section{Time dependence of BrdUrd incorporation}

Since most current and planned clinical protocols call for the continuous administration of BrdUrd of IdUrd for several weeks, the characterization of the kinetics of incorporation of these agents might be important to their clinical application. We chose to use $10 \mu M$ BrdUrd in these studies, since this concentration gave ample incorporation in a 24-h treatment, was only moderately toxic, and is in the range of concentrations observed clinically. No obvious morphological changes were observed after a 7-day treatment (with daily medium changes) at this concentration.

Figure 3 shows the extent of incorporation observed at various time points during a 1-week exposure of HT29 cells to BrdUrd, with the medium changed daily to avoid depletion of drug. Using the average doubling time observed for such a treatment $(35.1 \mathrm{~h}$, Table 1$)$, we calculated the expected course of this parameter over time, assuming that during each round of replication dThd was replaced by BrdUrd to an extent of either $100 \%$ (open squares) or $80 \%$ (open triangles). Based on the observed level of incorporation after $24 \mathrm{~h}(38.9 \%)$, we expected that the extent of replacement should have followed the latter time course, approaching a plateau value of $75 \%-80 \%$. In contrast, we observed that the level of incorporation not only failed to reach this theoretical limit but decreased significantly between 72 and $168 \mathrm{~h}(P<0.05)$.

One possible explanation for this observation is that the cells were exposed to a lower effective concentration of BrdUrd at later time points due to removal of BrdUrd from the medium. Since Wolff and Fijtman [28] had previously reported that the BrdUrd concentration of medium 


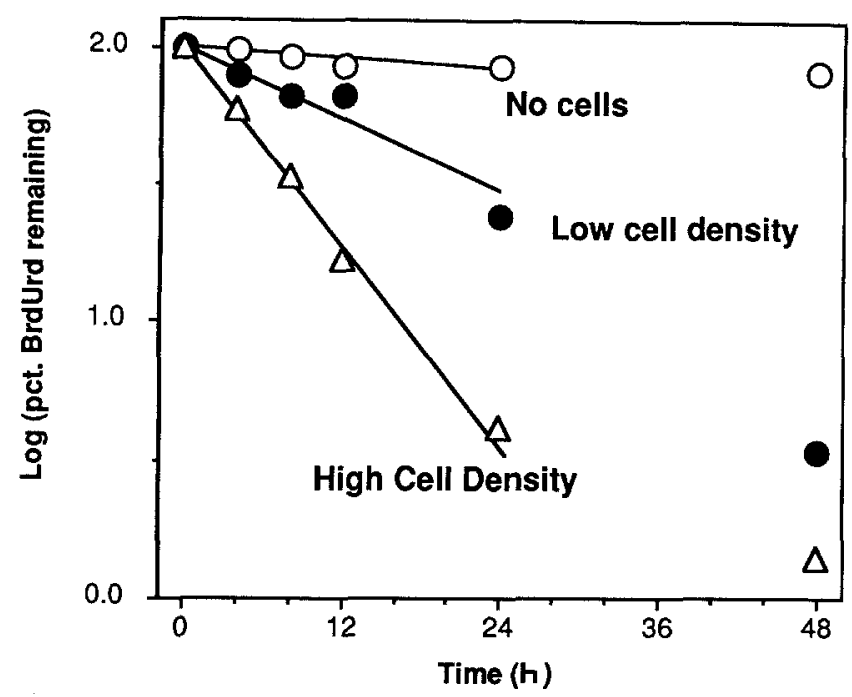

Fig. 4. Cell-mediated loss of BrdUrd from medium. Cells were plated in $150-\mathrm{cm}^{2}$ flasks at either 20,000 or $80,000 \mathrm{cells} / \mathrm{cm}^{2}$ and, after $48 \mathrm{~h}$ incubation in control medium, exposed to $30 \mathrm{ml}$ medium containing $10 \mu M$ BrdUrd. Samples of $3 \mathrm{ml}$ medium were collected at the indicated times and analyzed for BrdUrd by HPLC. Based on the first five time points, the apparent half-life for loss of BrdUrd was $12.0 \mathrm{~h}$ for the low-cell-density treatment and $5.2 \mathrm{~h}$ for the high-cell-density treatment. A duplicate experiment yielded virtually identical results

incubated with $\mathrm{CHO}$ cells declined over time, we measured the disappearance of drug from the medium in the presence of two different densities of cells or in the absence of cells (Fig. 4). This experiment indicated that the loss of BrdUrd was quite significant under the conditions applied and that this disappearance was related to the number of cells present. It is therefore likely that during each 24-h exposure interval, the cells entering S-phase toward the end of the period were synthesizing DNA in the presence of one-third to one-fourth of the nominal drug concentration.

Over the course of several days, it seems likely that asynchronously growing cells would enter S-phase at various times relative to medium changes and that the resulting population should contain a reasonably homogeneous level of incorporated DNA per cell, although within each cell of the population the incorporated analog is likely to be distributed in a nonuniform manner. However, in experiments using shorter treatment durations (i.e., $1-2$ cell cycles), the cell-to-cell heterogeneity of incorporation might be more severe. Heterogeneity of incorporation among cells in a given population could have a significant impact on the interpretation of experiments involving

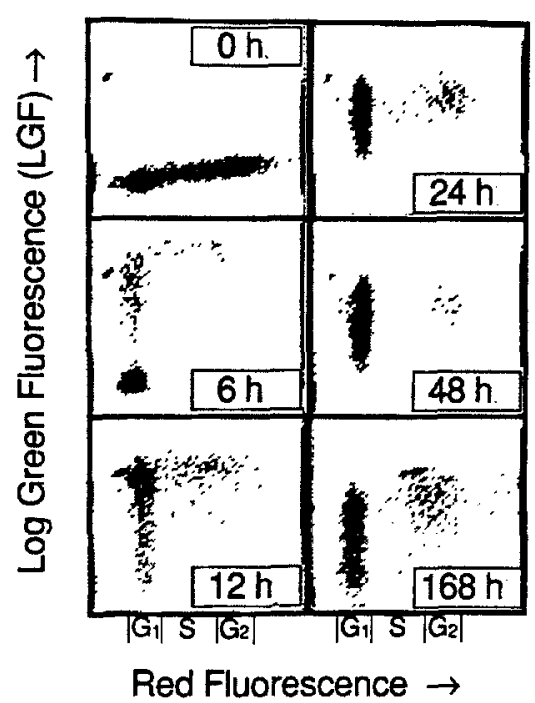

Fig. 5. Flow cytometric analysis of BrdUrd incorporation. Cells were continuously exposed to $10 \mu M \mathrm{BrdUrd}$ for the indicated times, with daily medium changes, after which they were fixed in ethanol. Analysis was carried out described in Materials and methods. Dual-parameter histograms are presented in which red fluorescence (apparent DNA content) increases along the abscissa and log green fluorescence (LGF, anti-BrdUrd antibody staining) increases along the ordinate. The data were obtained from one experiment that was representative of a total of five similar experiments

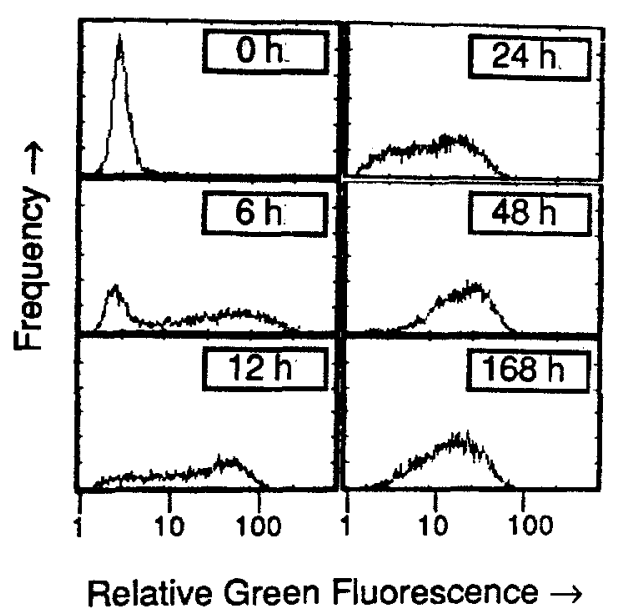

Fig. 6. Time-dependent loss of green fluorescence in G1 cells. These data are derived from the histograms shown in Fig. 5. Vertical cursors were set to include only cells having a G1 complement of DNA. The log green fluorescence values for this subpopulation were then plotted vs frequency of occurrence

Table 1. Growth inhibition and cell loss during 7-day exposure to $10 \mu M$ BrdUrd

\begin{tabular}{|c|c|c|c|c|c|}
\hline \multirow[t]{2}{*}{ Treatment } & \multirow{2}{*}{$\begin{array}{l}\text { Cell growth } \\
\text { over } 7 \text { days }\end{array}$} & \multirow{2}{*}{$\begin{array}{l}\text { Population } \\
\text { doublings }\end{array}$} & \multirow{2}{*}{$\begin{array}{l}\text { Average } \\
\text { doubling } \\
\text { time }\end{array}$} & \multicolumn{2}{|c|}{ Cells lost during 7-day treatment: } \\
\hline & & & & Number & Percentage of final count \\
\hline $10 \mu M$ BrdUrd & $0.55( \pm 0.06) \times 10^{7}$ & 4.79 & $35.1 \mathrm{~h}$ & $1.77 \times 10^{5}$ & $3.1 \%$ \\
\hline
\end{tabular}

a $\pm \mathrm{SD} ; n=4$ for control, 3 for BrdUrd treatment 
radiosensitization or chemosensitization, since the curves generated in such experiments are largely determined by points at which small fractions of cells survive (e.g. $[1,14,18]$ ).

\section{Flow cytometric determination of incorporated BrdUrd}

The recent availability of antibodies that recognize incorporated halopyrimidines facilitates studies on the population heterogeneity of incorporation of these agents [27]. It has also been suggested that these antibodies might be useful in the quantitative determination of BrdUrd or IdUrd incorporation in tissue or tumor specimens from patients. Although staining with anti-BrdUrd antibodies appears to correlate well with incorporation after relatively brief drug exposures [7], the relationship between antibody staining and extent of incorporation has not been evaluated in cells exposed to these agents for extended periods of time. We therefore carried out experiments in which HT29 cells were chronically treated with BrdUrd for 7 days, with daily medium changes, and cells were periodically harvested for analysis by dual-parameter flow cytometry.

Results of these studies appear in Figs. 5 and 6. Figure 5 shows a two-parameter $(2 P)$ analysis of the samples, with red fluorescence (DNA content) on the $\mathrm{X}$-axis and log green fluorescence (anti-BrdUrd $\mathrm{Ab}$ ) on the $\mathrm{y}$-axis. The cluster appearing in the upper left-hand corner of this graph represents fluorescent beads, which were added as internal standards for detecting changes in machine performance during the analysis. To show more clearly changes in green fluorescence over time, we present in Fig. 6 a series of oneparameter (IP) plots of the Gl cells only, showing log green fluorescence of these cells on the $\mathrm{x}$-axis vs frequency of occurrence on the $y$-axis.

The almost horizontal 2P distribution at $t=0$ (Fig. 5) is indicative of a population with only background green fluorescence, as is the 1P histogram (Fig. 6), which has a single peak at low log green fluorescence (LGF). At $t=6$ and $t=12$, there are a number of G1 (and S-phase) cells exhibiting positive green fluorescence in the $2 \mathrm{P}$ plot, which appear in the $1 \mathrm{P}$ plot as a new population with high LGF values. By $t=24$ virtually all of the cells show positive green fluorescence, although the mean intensity of this fluorescence has begun to decline. This decrease continues at $t=48$; at $t=168 \mathrm{~h}$, despite 1 week of continuous exposure to $10 \mu M$ BrdUrd, some cells have LGF values as low as those in untreated cells. The position of the standard beads remained constant throughout the analysis.

The data obtained at early time points in this experiment $(-24 \mathrm{~h})$ clearly show that virtually all members of the HT29 cell populations used in our studies could initially incorporate BrdUrd and that highly resistant subpopulations apparently did not preexist to any significant degree. The data from later time points indicate a substantial timedependent fall in the mean fluorescence of the cell population. At $t=168,25 \%$ of the G1 cells had values for green fluorescence as low as those at $t=0$. In a broad sense, this result is consistent with the decline in incorporation seen in Fig. 3. However, the decrease in fluorescence values apparently began after $24 \mathrm{~h}$, whereas incorporation values did not decline until after $72 \mathrm{~h}$. In Fig. 7 , we plotted the mean incorporation values from Fig. 3 along with the observed mean channel number for log green fluorescence (for G1 cell) from six samples derived from three separate

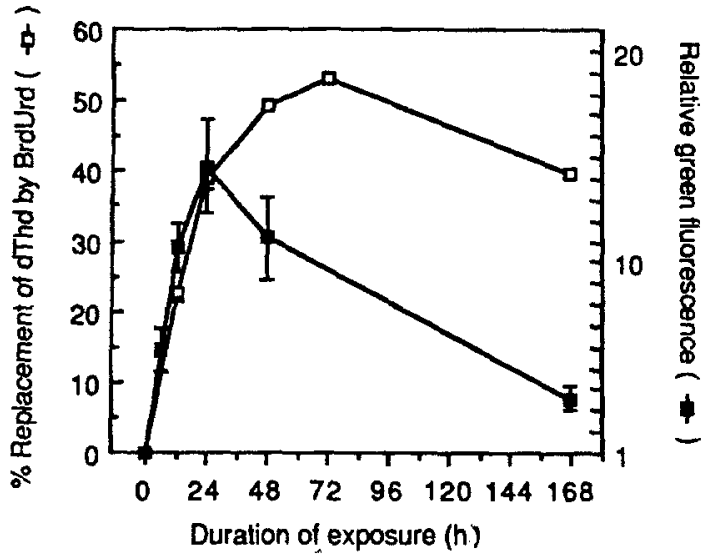

Fig. 7. Comparison of flow cytometric and GC/MS-SIM incorporation data as a function of time. Open squares represent the same data shown in Fig. 3. Filled squares represent the relative mean fluorescence (converted to a linear scale) of $\mathrm{G} 1$ cell populations similar to those shown in Fig. 6. The points represent the mean of three separate experiments (six samples) $\pm \mathrm{SE}$

experiments. These data confirm that loss of fluorescence in this system began well in advance of the loss of incorporated analog as measured by GC/MS. In addition, it should be noted that since a decrease of 23 channels in log fluorescence is equal to a $50 \%$ decline in linear green fluorescence, the apparent loss of incorporated BrdUrd described by this method is on the order of $75 \%$.

One explanation of these data would be that some portion of the antibody-staining procedure is antagonized after the first cell cycle, thereby resulting in artificially low green fluorescence values. Since previous studies have demonstrated that the presence of incorporated BrdUrd can dramatically increase the affinity of histones for DNA [11], it is possible that the chromatin containing. BrdUrd may condense into a form more resistant than native chromatin to the denaturation method used in the present study. Previous reports have demonstrated that BrdUrd incorporation can antagonize thermal denaturation of DNA $[5,19]$. It has also been suggested that at high levels of BrdUrd incorporation there may be a loss of stoichiometric antibody binding due to steric hindrance. (F. Dolbeare, unpublished data). Whether or not these mechanisms are correct, our data illustrate that although anti-BrdUrd antibodies may be useful for quantitation following relatively short exposures, experiments in which cells are treated with the analog for extended periods of time should be interpreted with caution.

In summary, we addressed three points that are pertinent to the use of BrdUrd as a regionally delivered radiosensitizer in tumors of colorectal origin. First, we illustrated that the high local concentrations of BrdUrd that can be established using regional infusion are significantly cytotoxic to a human colorectal tumor cell line. Second, our data demonstrate that even daily medium changes may not be sufficient to provide continuous exposure to BrdUrd. Finally, although the use of anti-BrdUrd antibodies provides useful information about the population heterogeneity in the uptake of this analog, their binding to DNA from cells exposed to BrdUrd may not be quantitatively indicative of the extent of BrdUrd incorporation under all conditions of cell growth. 
Acknowledgements. We wish to thank Dr. Frank Dolbeare for his generous gift of IU-4 antibody and for helpful discussions during preparation of the manuscript. This work was supported in part by NIH grants CA40260 and CA42761.

\section{References}

1. Ackland SP, Schilsky RL, Beckett MA, Weichselbaum PR (1988) Synergistic cytotoxicity and DNA strand break formation by bromodeoxyuridine and bleomycin in human tumor cells. Cancer Res 48: 4244

2. Beisker W, Dolbeare F, Gray JW (1987) An improved immunocytochemical procedure for high-sensitivity detection of incorporated bromodeoxyuridine. Cytometry 8:235

3. Brennan CA, Van Cleve MD, Gumport RI (1986) The effects of base analogue substitutions on the cleavage by the EcoRI restriction endonuclease of octadeoxyribonucleotides containing modified EcoRI recognition sequences. J Biol Chem 261: 7270

4. Caruthers MH, Beaucage SL, Efcavitch JW, Fisher EF, Goldman RA, de Haseth PL, Mandecki W, Matteucci MD, Rosendahl MS, Stabinsky Y (1983) Chemical synthesis and biological studies on mutated gene-control regions. Cold Spring Harbor Symp Quant Biol 47: 411

5. David J, Gordon JS, Rutter WJ (1974) Increased thermal stability of chromatin containing 5-bromodeoxyuridine-substituted DNA. Proc Natl Acad Sci USA 71: 2808

6. Dewey WC, Humphrey RM (1965) Increase in radiosensitivity to ionizing radiation related to replacement of thymidine in mammalian cells with 5-bromodeoxyuridine. Radiation Res 23: 538

7. Dolbeare F, Gratzner H, Pallavicini MG, Gray JW (1983) Flow cytometric measurement of total DNA content and incorporated bromodeoxyuridine. Proc Natl Acad Sci USA 80: 5573

8. Dolbeare F, Beisker W, Pallavicini MG, Vanderlaan M, Gray JW (1985) Cytochemistry for bromodeoxyuridine/DNA analysis: stoichiometry and sensitivity. Cytometry $6: 521$

9. Ensminger W (1989) Hepatic arterial chemotherapy for primary and metastatic liver cancers. Cancer Chemother Pharmacol (in press)

10. Erikson RL, Szybalski W (1963) Molecular radiobiology of human cell lines: V. Comparative radiosensitizing properties of 5-halodeoxycytidines and 5-halodeoxyuridines. Radiation Res 20: 252

11. Gordon JS, Bell GI, Martinson HC, Rutter WJ (1976) Selective interaction of 5'-bromodeoxyuridine-substituted DNA with different chromosomal proteins. Biochemistry 15:4778

12. Goz B (1977) The effects of incorporation of 5-halogenated deoxyuridines into the DNA of eukaryotic cells. Pharmacol Rev 29: 249

13. Hoshino T, Nagashima T, Cho KG, Murovic JA, Hodes JE, Wilson CB, Edwards MSB, Pitts LH (1986) S-phase fraction of human brain tumors in situ measured by uptake of bromodeoxyuridine. Int $\mathbf{J}$ Cancer 38:369

14. Iliakis G, Wright E, Ngo FQH (1987) Possible importance of PLD repair in the modulation of BrdUrd and IdUrd-mediated radiosensitization in plateau-phase $\mathrm{C} 3 \mathrm{H} 10 \mathrm{Tl} / 2$ mouse embryo cells. Int J Radiat Biol 51 : 541
15. Kaufmann ER, Davidson RL (1977) Novel phenotypes arising from selection of hamster melanoma cells for resistance to BUdR. Exp Cell Res 107: 15

16. Kinsella TJ, Mitchell JB, Russo A, Aiken M, Morstyn G, Hsu SM, Rowland J, Glatstein E (1984) continuous intravenous infusions of bromodeoxyuridine as a clinical radiosensitizer. J Clin Oncol 2: 1144

17. Kinsella TJ, Russo A, Mitchell JB, Collins JM, Rowland J, Wright D, Glatstein E (1985) A phase I study of intravenous iododeoxyuridine as a clinical radiosensitizer. Int $\mathrm{J}$ Radiat Oncol Biol Phys 11: 1941

18. Kinsella TJ, Dobson PP, Mitchell JB, Fornace AJ (1987) Enhancement of X-ray-induced DNA damage by pre-treatment with halogenated pyrimidine analogs. Int $\mathbf{J}$ Radiat Oncol Biol Phys 13: 733

19. Kit S, Hsu TC (1961) Relative stability to thermal denaturation of deoxyribonucleic acid (DNA) preparations containing bromodeoxyuridine. Biochem Biophys Res Commun 5: 120

20. Maybaum J, Kott MG, Johnson NJ, Ensminger WD, Stetson PL (1987) Analysis of bromodeoxyuridine incorporation into DNA: comparison of gas chromatographic/mass spectrometric, $\mathrm{CsCl}$ gradient sedimentation, and specific radioactivity methods. Anal Biochem 161:164

21. Morstyn G, Hsu S-M, Kinsella T, Gratzner H, Russo A, Mitchell JB (1983) Bromodeoxyuridine in tumors and chromosomes detected with a monoclonal antibody. J Clin Invest 72 : 1844

22. Reff ME, Davidson RL (1979) Deoxycytidine reverses the suppression of pigmentation caused by 5-Brd-Urd without changing the distribution of 5-Brd-Urd in DNA. J Biol Chem 254: 6869

23. Stetson PL, Shukla UA, Amin PR, Ensminger WD (1985) High-performance liquid chromatographic method for the determination of bromodeoxyuridine and its major metabolite, bromouracil, in biological fluids. J Chromatogr $341: 217$

24. Stetson PL, Maybaum J, Shukla UA, Ensminger WD (1986) Simultaneous determination of thymine and 5-bromouracil in DNA hydrolysates using gas chromatography-mass spectrometry with selected-ion monitoring. J Chromatogr $375: 1$

25. Stetson PL, Maybaum J, Wagner JG, Averill DR, Wollner IS, Knol JA, Johnson NJ, Yang Z, Preiskorn D, Smith P, Knutsen CA, Ensminger WD (1988) Tissue-specific pharmacodynamics of 5-bromo-2'-deoxyuridine incorporation into DNA in VX2 tumor-bearing rabbits. Cancer Res 48: 6900

26. Szybalski W (1974) X-ray sensitization by halopyrimidines. Cancer Chemother Rep 58: 539

27. Vanderlaan M, Watkins B, Thomas C, Dolbeare F, Stanker L (1986) Improved high-affinity monoclonal antibody to iododeoxyuridine. Cytometry 7:499

28. Wolff S, Fijtman N (1981) X-ray sensitization of chromatids with unifilarly and bifilarly substituted DNA. Mutat Res 80: 133

Received 16 August 1988/Accepted 11 April 1989 